\title{
Effect of Using Air Guide Net in Front of the Condenser on the Performance of Automobile Air Conditioning System
}

\author{
Mahmoud Maustafa Mahdi* A. A. Gaddoa** \\ ***Department of Electromechanical Engineering/University of Technology/ Baghdad/Iraq \\ *Email: Mahmoud_mahdi74@yahoo.com \\ **Email: en_ameerabed@yahoo.com
}

(Received 5 September 2018; accepted 19 February 2019)

https://doi.org/10.22153/kej.2019.02.001

\begin{abstract}
The work of this paper is an investigation to improve the condenser performance of the automobile air conditioning system by enhancing the air-side heat transfer from the condenser through the use of an air guide net installed in front of the condenser face which is basically an aluminum plate having a circular entrance shape for the air passage. The A/C system was examined under two types of test. The first test was conducted the air guide net, while the second was done with the air guide net. The performances of the $\mathrm{A} / \mathrm{C}$ system under these tests were compared. For the second type of test, the experiment was carried out with three different size of air guide net, three different circular diameters $(2,3$ and $3.5 \mathrm{~cm}$ ) and a common air passage area. The effect of varying the size of the air guide net and its inclination angle was investigated. The experimental work included five inclination angles $\left(0^{\circ}, 5^{\circ}, 10^{\circ}, 15^{\circ}\right.$ and $\left.20^{\circ}\right)$. It was found that the presence of the air guide net caused an improvement in the performance of the $\mathrm{A} / \mathrm{C}$ system for all sizes and inclination angles. In addition, the electrical energy consumed by the $\mathrm{A} / \mathrm{C}$ system without the air guide net was calculated and compared to those obtained for the $\mathrm{A} / \mathrm{C}$ system with the air guide net. The results manifested that the reduction of the power consumption was enhanced by operating the $\mathrm{A} / \mathrm{C}$ system with the air guide net.
\end{abstract}

Keywords: Automobile A/C system, Coefficient of performance, Air guide net, Experimental investigation.

\section{Introduction}

Refrigeration systems are widely used in commercial buildings, offices, airport, and hospital and in automobiles. Automobile air conditioning system is the biggest auxiliary load on the vehicle engine (internal combustion engine cars). It consumes a large amount of energy up to $30 \%$ of the fuel. Alison, et al. [1]. Fortunately, there are various ways to improve the coefficient of the performance of the $\mathrm{A} / \mathrm{C}$ system, such as enhancement the performance of the condenser component. In order to enhance the performance of the condenser, it is important to enhance the air side heat transfer which is the dominant one. Automotive A/C system is mainly consisting of a condenser, a compressor, an expansion value and an evaporator. Some significant characteristics that effect on the performance of the automotive $\mathrm{A} / \mathrm{C}$ system more are complicated than the other $\mathrm{A} / \mathrm{C}$ systems, Bhatti [2]; and Kiatsiriroat, and Euakit. [3]. The actual performance of the automotive air conditioning system is a result of the balancing among the essential cycle components when the performance of any above components of the air-conditioning system varies as a result of one or more effecting factors, and this will reflect on the performance of the other component of the A/C system. One of the effecting factors on the performance of the condenser component is the air side heat transfer coefficient. When the air side heat transfer coefficient varies, it affects the performance of the condenser, which in turn affects the performance of the other components of the $\mathrm{A} / \mathrm{C}$ system. 
Jabordo et al. [4] analyzed an automotive A/C system, focusing on the relation between the C.O.P and compressor capacity. Schwarz et al. [5] experimentally determine the flow inside the accumulator of the $\mathrm{A} / \mathrm{C}$ system of an automotive. They found that the flow inside the accumulator is critical to the coefficient of performance of the $\mathrm{A} / \mathrm{C}$ system, lubrication and safety for the compressor.

Awaji et al. [6] studied the two-phase flow inside the evaporator of $\mathrm{A} / \mathrm{C}$ system and found the effect of the flow on the heat transfer performance of the evaporator component. Joudi et al. [7] noticed that the experimental analysis is an effective method for analyzing the automotive A/C system. Shu, and Hany [8] analyzed the split of residential water-cooled air conditioning system. They determined that the water used in cooling the condenser resulted in decreasing in the energy consumption of the compressor from 1.189 to $1.02 \mathrm{KW}$ and an increasing in the C.O.P of the A/C system from 2.96 to 3.45 .

YU, and Chan [9] improved the C.O.P. of an air-cooled chiller by using variable speed condenser fan to modulate the heat rejection air flow. They presented a program to determine the number and the speed of the fans used to cool the condenser and to provide the required air flow for a given condenser heat rejection.

Jiang et al. [10] showed how the condensing recovery affects the cooling and the average C.O.P of A/C system. Amarnath [11] investigated the effect of condenser heat exchanger on the C.O.P of the A/C system. He found that increasing the condenser area will ensure more heat transfer to the surroundings from the condenser component of $\mathrm{A} / \mathrm{C}$ system, which increases sub cooling. Aby et al. [12] experimentally investigated the various types of condenser on the performance of vapor compression cooling system in order to reduce the energy consumption of the system. In addition, they studied the effect of many parameters, such as the air flow rate and the condenser heat transfer coefficient on the C.O.P. of the system. It was found that the evaporative condenser enhanced the process of condenser heat rejection and therefor improved the reduction of energy consumption.

Improving the performance of the condenser component of an $\mathrm{A} / \mathrm{C}$ system can be achieved by multiple techniques. The enhancement of condensation heat transfer coefficient has been investigated by many authors, including Choui [13], Coleman and S. Gaarimella [14] and Bari et al. [15].
Varma, and Gupta [16] determined the effectiveness of an air conditioning condenser and noticed that in some applications, the air flow nonuniformity affects the thermal performance of the condenser component. A wad et al. [17] investigated the effect of inclination angle of flat tubes condenser on the convection air side heat transfer coefficient. They found an optimum angle of $4^{\circ}$, which offered the best enhancement in the air side heat transfer performance. Song et al. [18] numerically and experimentally investigated the impact of non-uniform air velocity distribution on the performance of the evaporator. They found that the capacity of the evaporator under uniform air velocity distribution was $7.78 \%$ higher than that under non-uniform velocity distribution. Zhaoying, and Jianguo Y. [19] determined the effect of face-air velocity distribution on the thermal performance of an air-cooled condenser of a power plant. They noticed that the distribution of the air velocity affects the thermal performance of the air cooled condenser.

As shown in the literature survey on the performance of the condenser component of $\mathrm{A} / \mathrm{C}$ system, it revealed that increasing the condenser heat rejection leads to the improvement of the refrigeration cycle performance system. Furthermore, in summary, the literature on guiding the cooling air flowing depicted that the guiding devices can make a better air flow uniformly and improve the heat transfer performance of an air cooled condenser of $\mathrm{A} / \mathrm{C}$ system. Therefore, the objective of this study is to:

1. Investigate the impact of using an air guide net in front of the condenser component on the performance of an air-cooled automobile training unit.

2. Evaluate the performance of automobile A/C system under different air guide net sizes and inclination angles and ultimately identify the optimum inclination angle of the air guide net corresponding to a better C.O.P of the system.

\section{Methodology}

The automobile A/C system is vapor compression refrigeration cycle. The vapor compression cycle is basically a system, which consists of an evaporator, a compressor, a condenser and an expansion device. Figure (1A) shows a typical schematic representation of the vapor compression refrigeration cycle.

The cycle can be divided down into the following stage, as shown in Figure (1B). 
Stage 1-2 Compressor: The energy equation, which represents the amount of the specific work done by the compressor, is:

$\mathrm{W}_{\text {compressor.s }}=\left(\mathrm{h}_{2 \mathrm{~s}}-\mathrm{h}_{1}\right)$

Where:

$\mathrm{h}_{1}=$ The enthalpy of working refrigerant entering the compressor.

$\mathrm{h}_{2 \mathrm{~s}}=$ The enthalpy of the working refrigerant that exits from an isentropic compressor.

The actual specific work required from a nonisentropic compressor is depending the efficiency:

$\mathrm{W}_{\text {compressor.a }}=\mathrm{W}_{\text {compressor.s }} / \eta_{\text {compressor }}$

Where: $\eta_{\text {compressor. }}=$ The thermal efficiency of the compressor.

The volumetric efficiency can be defined as the ratio of the vapor mass that is compressed to the vapor mass that compressed ideally. The volumetric efficiency of compressor is:

$\eta_{\mathrm{v}}=1-\mathrm{R}_{\mathrm{p}, \mathrm{c}}\left[\left(v_{1} / v_{2}\right)-1\right]$

Where:

$\eta_{\mathrm{v}}=$ The volumetric efficiency of the compressor.

$\mathrm{R}_{\mathrm{p}, \mathrm{c}}=$ Ratio (piston / cylinder) of clearance volume to the swept displacement.

$v_{1}=$ The entering specific volume to the compressor.

$v_{2}=$ the existing specific volume from the compressor.

The volumetric efficiency can be used to determine the mass flow rate of the refrigerant that enters and exits from the compressor.

$\mathrm{m}^{*}=\left(\eta_{\mathrm{v}} \times \mathrm{p}_{\mathrm{D}}\right) / \mathrm{v}_{2}$

Where:

$\mathrm{p}_{\mathrm{D}}=$ The displacement of the piston.

Stage 2-3 Condenser: The heat rejected in the condenser from the refrigerant (working fluid) to the air side at the outside condenser face is:

$\mathrm{Q}_{\text {condenser }}=\mathrm{h}_{2}-\mathrm{h}_{2 \mathrm{a}}$

Stage 3-4 Expansion device: Across the expansion valve the equation of energy shows that the enthalpy is maintained constant.

$\mathrm{h}_{3}=\mathrm{h}_{4}$

Stage 4-1 Evaporator: The specific heat absorbed can be determined by the refrigerant enthalpies at the inlet and outlet of the evaporator.

$\mathrm{Q}_{\text {evaporator }}=\left(\mathrm{h}_{4}-\mathrm{h}_{1}\right)$

The overall performance of the cycle system can be evaluated by the coefficient of performance (C.O.P).

C.O.P $=\mathrm{Q}_{\text {evaporator }} / \mathrm{W}_{\mathrm{p}}$

Where:

$\mathrm{W}_{\mathrm{p}}=$ The electric energy required by the cycle system.

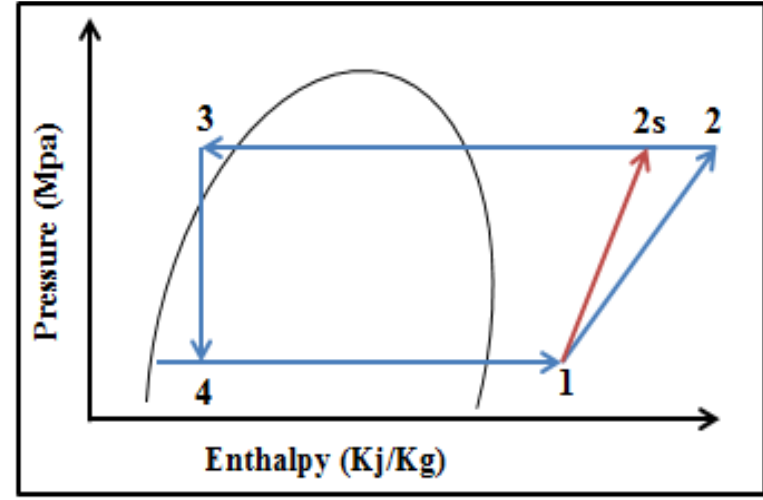

Fig. 1A. Schematic of the vapor compression refrigeration cycle.

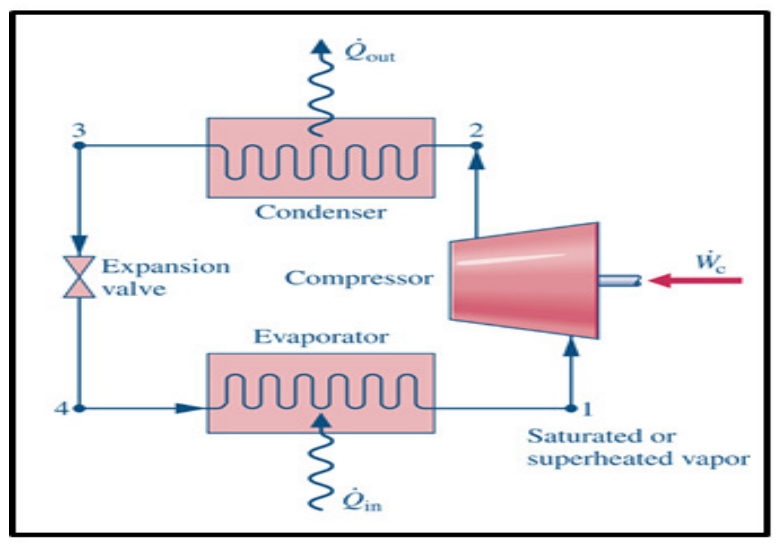

Fig. 1 B. Refrigeration air conditioning system

\section{Experimental Apparatus and test procedure}

An automobile A/C training system, $(3 \mathrm{KW})$ cooling capacity, using (HFC-R134a), was selected for the tests. The A/C system contains the basic components corresponding to the vapor compression system: an evaporator, a condenser, a compressor and an expansion device and such attachments self-closing valve: Schrader type, a dehydrating filter and a pressure switch (trinity type).

Figure (2) displays the schematic illustration of the experimental setup used in this investigation. 


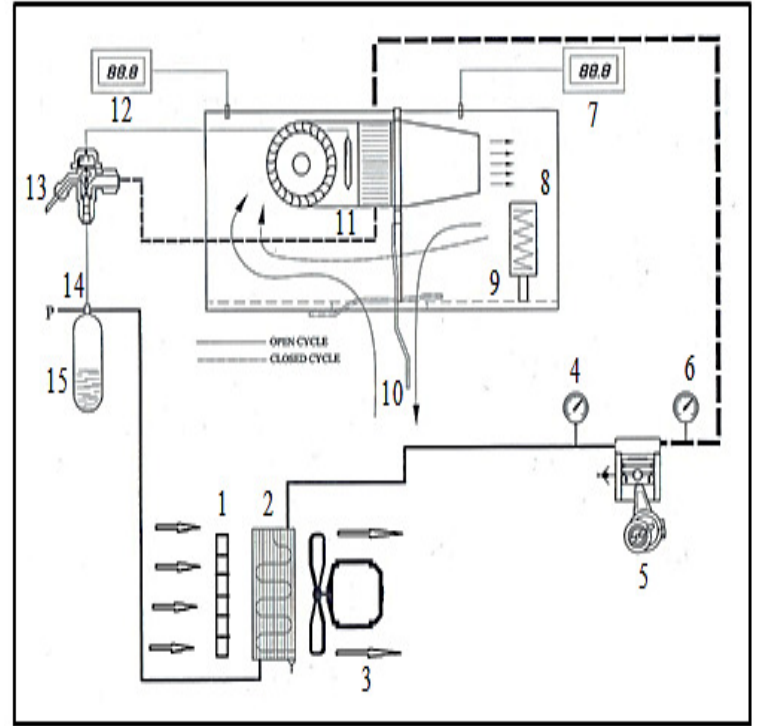

Fig. 2. Instruments of automobile air conditioner training unit: 1-Air guide net, 2- Condenser, 3Condenser fan, 4-Low pressure manometer,5Compressor, 6-High pressure manometer, 7-Indoor temperature display, 8-Electrical resistance (human body heat simulator, 9-Low pressure switch, 10Control board, 11-Evaporator, 12-Outdoor temperature display, 13-Therostatic expansion valve, 14-Low pressure switch, 15-Filter drier.

The air-cooled condenser stands with a cooling capacity of $4.5 \mathrm{KW}$. The condenser undergoes cooling through a forced convection by the condenser fan, which was employed to extract the room air through the condenser component and discharge it outside the $\mathrm{A} / \mathrm{C}$ system unit, as shown in Figure (3).

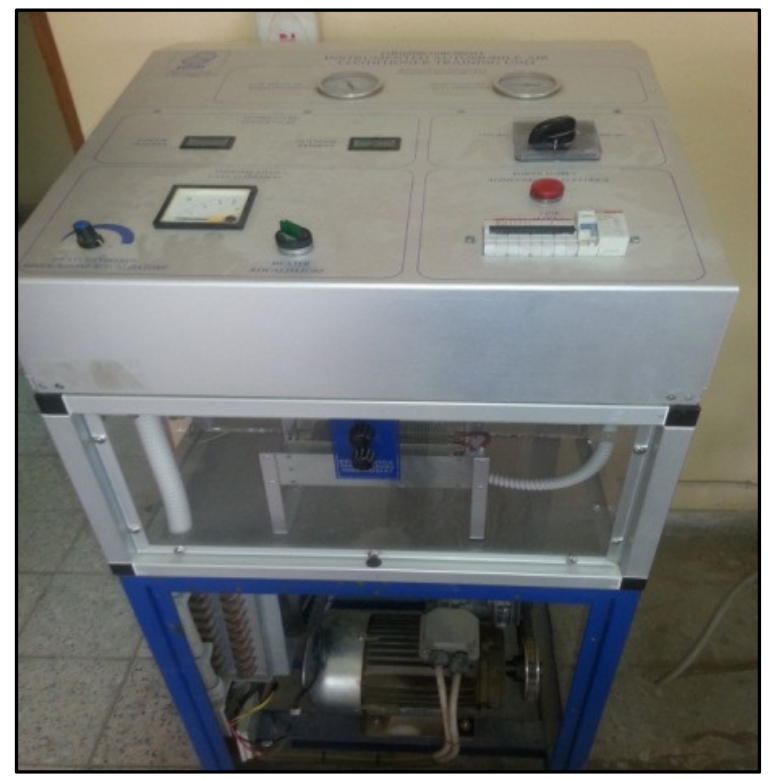

Fig. 3. An automobile A/C training system.
The evaporator was insulated so that the heater power input can be considered as the cooling capacity (or human body heat simulator). A thermostatic expansion valve was used as an expansion device to change the sub-cooled liquid (with higher pressure) into vapor-liquid mixture (with lower pressure). A measurement system and controls were set-up to conduct the data processing and to control the $\mathrm{A} / \mathrm{C}$ system operation. The temperature (or the condition) of the air at the front of the condenser face was measured by a digital temperatures humidity meter. Figure (4) manifests the front view of the two different condenser configurations, namely without an air guide net and with air guide net.

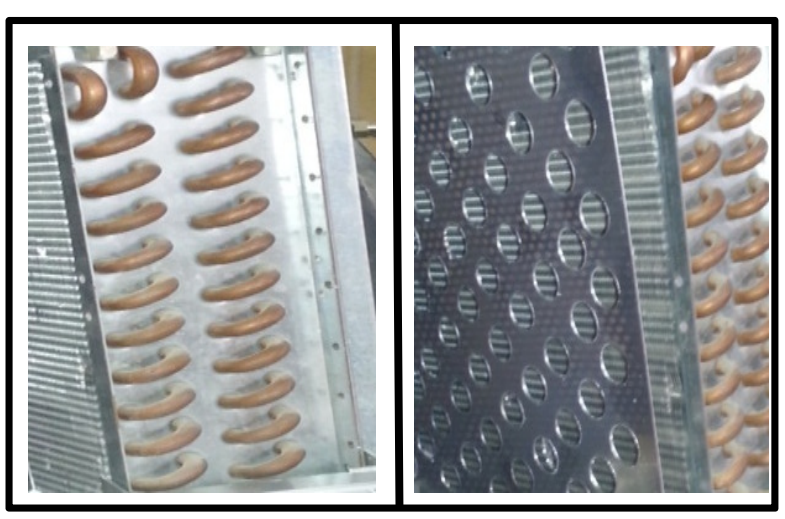

(a)

(b)

Fig. 4. Front view of the two different condensers, (a) without guide net and (b) with air guide net.

An air guide net is basically a plate with circular holes drilled in order to allow the air pass through it before passing the face of the condenser, used and placed in front of the condenser face, in order to change the air velocity distribution upstream the condenser face and hence to find its effect on the performance on the $\mathrm{A} / \mathrm{C}$ system, as shown in Figure (4). The air guide net was made of $1 \mathrm{~mm}$ aluminum plate. The plate was drilled to provide the necessary access for the air passing through it, so, the plate contained holes. Three different air guide nets having different hole radius $(1,1.5$ and $1.75 \mathrm{~cm})$ were tested. The system power consumption was measured by a digital wattmeter. By this system, the pressure, temperature and power were measured. All the measured data were processed to calculate other parameters. Also, this system can operate the $\mathrm{A} / \mathrm{C}$ system under controlling, such as turning the power off or on and adjusting the speed of the compressor. Experiments were 
carried out on the automobile $\mathrm{A} / \mathrm{C}$ system with and without an air guide net. The system was tested under the same conditions. Initially, the apparatus was switched on. Full air flow rate was adjusted by the condenser fan. The temperature of the air, which cooled the condenser, is kept constant at $38{ }^{\circ} \mathrm{C}$ during these experiments. Approximately $30 \mathrm{~min}$ were required to reach the steady state. After the steady state condition, the average values of each experimental variable (temperature, pressure and power consumption) were collected. After the collection of all data for the (case without air guide net) performed, the air guide net was put in front of the condenser face so that a new experimental configuration was tested. Table (1) lists the geometrical dimensions of the air guide net samples. The same procedure was repeated for each of various experimental air guide net sizes. For each air guide net size of the second group, the inclination angle of the air guide net was varied to determine the effect of inclination angle on the performance of the $\mathrm{A} / \mathrm{C}$ system and to obtain the better inclination angle that gives a maximum C.O.P of the A/C system. Table (2) reveals a brief outline of the experimental program.

Table 1,

Geometric dimensions of the air guide net.

\begin{tabular}{llllll}
\hline $\begin{array}{l}\text { Air guide net } \\
\text { sample }\end{array}$ & $\begin{array}{l}\text { Air guide net } \\
\text { dimension }(\mathbf{c m})\end{array}$ & $\begin{array}{l}\text { Air guide net size } \\
\text { hole radius }(\mathbf{c m})\end{array}$ & $\begin{array}{l}\text { Air side passage } \\
\text { area }\left(\mathbf{c m}^{\mathbf{2}}\right)\end{array}$ & $\begin{array}{l}\text { No. of } \\
\text { holes }\end{array}$ & $\begin{array}{l}\text { face condenser } \\
\text { area blocked }(\%)\end{array}$ \\
\hline 1 & $33 \times 33$ & 1 & 546.6 & 174 & $50.19 \%$ \\
2 & $33 \times 33$ & 1.5 & 544.2 & 77 & $50 \%$ \\
3 & $33 \times 33$ & 1.75 & 548 & 57 & $50.3 \%$ \\
\hline
\end{tabular}

Table 2,

A brief outline of the experimental program.

\begin{tabular}{lll}
\hline Type of testing the A/C system & Air guide net size hole radius $(\mathbf{c m})$ & Inclination angle (degree) \\
\hline $\begin{array}{l}\text { Testing the A/C system without an air } \\
\text { guide net first group }\end{array}$ & ------ & --- \\
$\begin{array}{l}\text { Testing the A/C system with an air guide } \\
\text { net second group }\end{array}$ & 1 & $0^{\circ}, 5^{\circ}, 10^{\circ}, 15^{\circ}, 20^{\circ}$ \\
& 1.5 & $0^{\circ}, 5^{\circ}, 10^{\circ}, 15^{\circ}, 20^{\circ}$ \\
& 1.75 & $0^{\circ}, 5^{\circ}, 10^{\circ}, 15^{\circ}, 20^{\circ}$ \\
\hline
\end{tabular}

\section{Results and Discussion}

Through these practical experiments, the nature and shape of the airway passing through the face of the condenser surface have been changed using a variety of air guide net sizes before the air enters the condenser. To illustrate the effect of placing these air guide nets in front of the surface of the condenser and to show the improved increasing of the heat rejection from the condenser, a comparison was made between the two cases (without and with using air guide net). The effect of the air guide net size (i.e. the hole size diameter) on the performance of $\mathrm{A} / \mathrm{C}$ system was investigated for the system of the second group. For the second group, experiments were carried out at three different air guide net sizes. In addition, based on the experimental results, of the second group, the performance of the $\mathrm{A} / \mathrm{C}$ system when changing the inclination angle of the air guide net was evaluated. The effect of various operating factors on the performance of the $\mathrm{A} / \mathrm{C}$ system will be discussed in the following sections. The parameters that affect the A/C system performance were considered for illustration. Several parameters were measured, charted and discussed, such as discharge temperature (working fluid inlet temperature to the condenser), C.O.P of the $\mathrm{A} / / \mathrm{C}$ system and system power consumption.

\subsection{The Effect of Air Guide Net on the Discharge Temperature (Td)}

Figure (5) elucidates the comparison between $\mathrm{A} / \mathrm{C}$ system without and with an air guide net for three different air guide net sizes. The effect of various air guide sizes on the discharge temperature is displayed in this figure at an inclination angle of $\left(0^{\circ}\right)$. It is clearly shown that the discharge temperature is on a higher side in the case without air guide net and low in the case with air guide net. The discharge temperature was observed between $\left(68.1^{\circ} \mathrm{C}\right.$ to $\left.64.2^{\circ} \mathrm{C}\right)$ in the case with air guide net. Also, the discharge temperature changing with the air guide net size by $\left(5^{\circ} \mathrm{C}\right)$ for sample $(1),\left(8.9^{\circ} \mathrm{C}\right)$ for sample $(2)$ and $\left(6.2^{\circ} \mathrm{C}\right)$ for sample (3) in comparing with the case without 
air guide net, that in mean the reduction in the discharge is about $(6.8 \%)$ for the air guide net sample (1), and about (12\%) for the air guide net sample (2), while at air guide net sample (3), the reduction is about $(8.6 \%)$ in comparison with the case without air guide net. The reduction in the discharge temperature can be attributed to the fact that the decreasing in the face area of the condenser leads to increasing the velocity of the air over the other part of the condenser by a higher percentage; i.e. when the face condenser area is reduced by $(50 \%)$, the velocity of the air across the rest of the condenser increases. This means increasing the air velocity is working against the loss in face area, i.e. offsetting completely the effect of the reduction in the condenser face area. As a result, the heat transfer coefficient of the air side increases by a higher percentage, because the air heat transfer coefficient is dependent on the Reynolds number (and thus velocity), also, the tubes and fins area ate free to conduct the heat to the condenser area, which is still exposed to the flow of the air. Furthermore, the $(50 \%)$ of the condenser area is still has free convection over it. In addition to that, the air with a higher velocity will still moving next to the fins to a certain extent because of the sudden expansion and contraction that the air flow gives behind the condenser and the forced convection will enhance the thermal heat transfer to a certain extent. The enhancement of the air side heat transfer coefficient is important in the two-phase region of the condenser, where more than $(80 \%)$ is air side resistance of the total resistance Choui [13]. That means the enhancement of the overall heat transfer coefficient of the condenser will occur. This enhancement (for the case with air guide net) makes the condenser need only a less two-phase area, hence, the percentage area of the two-phase region has increased. This makes the superheated transient point slowly move down stream (i.e. reducing the discharge temperature of the working fluid (R134a). The movement of the superheated region causes a greater percentage of the condenser size to be two-phase replacing the superheated region.

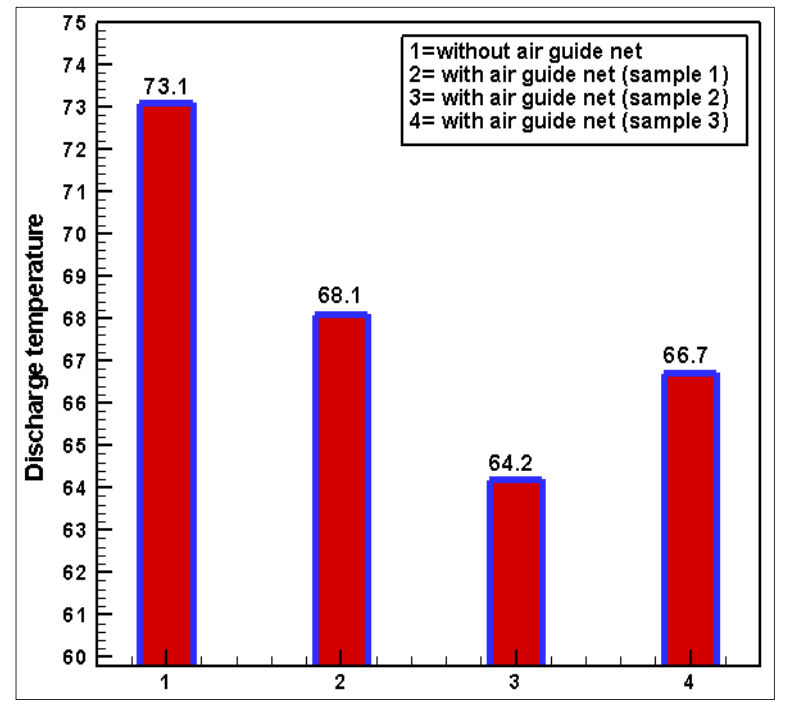

Fig. 5. Comparison of discharge temperature $\left(T_{D}\right)$ between with and without air guide net.

\subsection{The Effect of Air Guide Net on the Cycle C.O.P.}

It was pointed out in the previous section that, by installing an air guide net upstream the condenser, the working fluid discharge temperature (R134a) decreases as a result of increasing the two-phase region of the condenser which makes the superheated transition point move down stream. Figure (6), evinces the variation of calculated cycle C.O.P of different air guide net samples. This figure also shows the comparison of the C.O.P of the A/C system for the three air guide net sizes (three samples) with that of no air guide net. The cycle C.O.P of the $\mathrm{A} / \mathrm{C}$ system is observed to be higher with air guide net. The air guide net size of sample (2) appears to give the best result in term of C.O.P in comparison with the other air guide net sizes (sample 1 and sample 3). It's observed from figure (6) that the minimum C.O.P (2.21) is reached in the case of without using of air guide net and maximum C.O.P (2.65) in the case of using an air guide of sample (2). These results can be attributed to two reasons. First, the objective of the air guide net is to direct the air stream in a direction perpendicular to the condenser face plane and when the air streams strike the face of the condenser, a large amount of heat dissipation from the condenser would be transferred to the air passing through the condenser. The second, the reduction of discharge temperature $\left(T_{d}\right)$ reduces the specific volume of the cycle working fluid (R134a) and thus increases the volumetric efficiency of the compressor in equation (3) which 
reduces the energy spent in the compressor. The reduction of energy spent in the compressor and with the same heat capacity at the evaporator lead to an improvement in the cycle C.O.P of the A/C system equation (8).

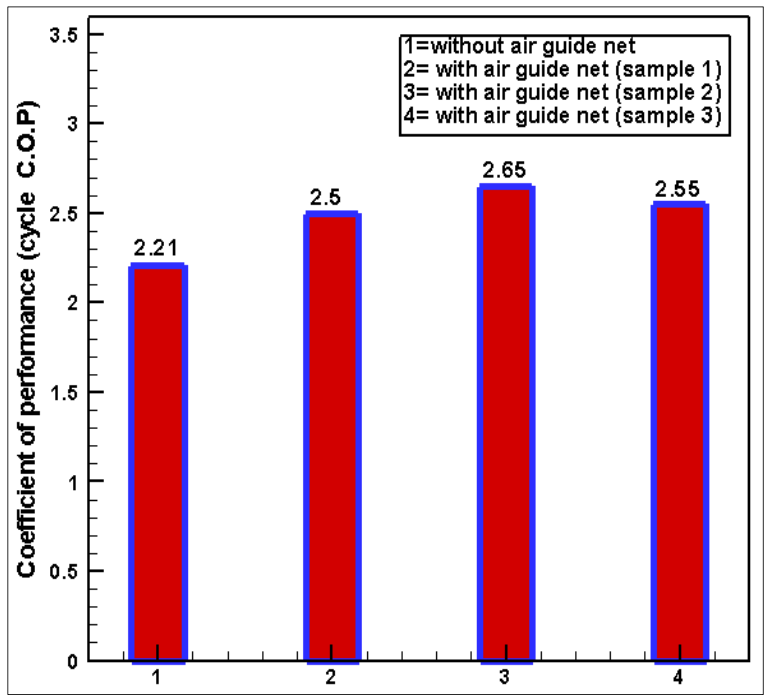

Fig. 6. Graphical representation of cycle C.O.P for the $\mathrm{A} / \mathrm{C}$ system with and without air guide net.

Figure (7) demonstrates the representation of the percentage increase of C.O.P for three different air guide net sizes. It can be seen from this figure that, the C.O.P increased by (13\%) for the case with an air guide net (sample 1) in comparison with the case without air guide net, while for the air guide net (sample 2), the increasing is about (17\%), also for the air guide net (sample 3), the increasing is about (14\%).

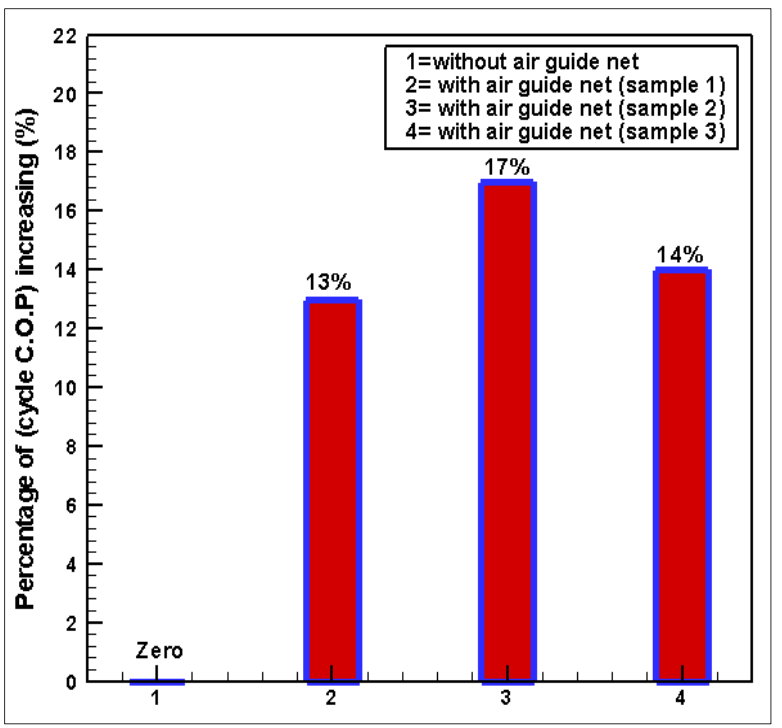

Fig. 7. Graphical representation of cycle C.O.P percentage increasing for the $\mathrm{A} / \mathrm{C}$.

\subsection{The Effect of Inclination Angle}

Based on the experimental results, the performance of the $\mathrm{A} / \mathrm{C}$ system when changing the inclination angle of the air guide net was evaluated. Different cycle C.O.P values under three different air guide net sizes (three samples) and five inclination angle are shown in Figure (8). In this figure, a typical variation of the cycle C.O.P with inclination angle from $\left(0^{\circ}\right.$ to $\left.20^{\circ}\right)$ is shown. As shown in this figure (8), the increase in the cycle C.O.P is small in the first part of the curves up to (10 degrees), then the cycle C.O.P increases sharply. Also, there are higher values of the cycle C.O.P in the second part of the curves. In the other words, for increasing inclination angle $\left(0^{\circ}\right)$ up to $\left(15^{\circ}\right)$ there is a continuous increase in the cycle C.O.P. Additionally, it is found that there is a peak value of inclination angle (at $\theta=15^{\circ}$ ). Then, the increase of $(\theta)$ more than (15) degree leads to decrease in the cycle C.O.P. This can be attributed to two reasons: the first, the varied parameters include the inlet air velocity profile and the air split between the upper and lower parts of the condenser, when the inclination angle of the air guide net changed, that means there was a significant difference in the amount of air flowing through the upper side and lower side of the condenser, i.e. more air passed through the upper part of the condenser than the lower part, and the upper part of the condenser had a higher air flow rate than the lower part. Thus, the upper part of the condenser is therefore capable of transferring a significant amount of heat which results in more heat dissipation from the condenser. This unbalanced air flow because the cycle working fluid (R134a) entering the upper part of the condenser has a lower level of superheat. The second reason is the redirecting air flow toward the low velocity area at the core of the condenser, as a result of changing the inclination angle of the air guide net. This low velocity area is caused by the hub of the condenser fan. Therefore, it can be concluded that, different face-air velocity distributions can be reached by various air guide net sizes and different inclination angles of the air guide net.

As shown in Figure (8), at a certain air guide net inclination angle $\left(0^{\circ}-15^{\circ}\right)$, the cycle C.O.P of the $\mathrm{A} / \mathrm{C}$ system increases, i.e., there is a peak value of inclination angle $\left(15^{\circ}\right)$. Therefore, it is reasonable to predict that the air side heat transfer coefficient can be increased roundly when the face-air velocity distribution through the condenser can be adjusted of $\left(13^{\circ}\right.$ to $\left.170^{\circ}\right)$ air guide net inclination angle. That means at this 
angle of inclination, the air side heat transfer coefficient of the condenser increases, therefore the thermal performance of the condenser (denoted by the air side convection heat transfer coefficient) will increase, if the face air velocity through the condenser is adjusted of the case to $\left(15^{\circ}\right)$ air guide net inclination angle. At this angle, the face air velocity distribution increases from bottom to top of the condenser, i.e the face air velocity distribution affects the thermoperformance of the condenser, which in turn affects the performance of the $\mathrm{A} / \mathrm{C}$ system. Therefore, the air velocity redistribution can be employed as an important rule for the enhancement of the thermal performance of the condenser component of the $\mathrm{A} / \mathrm{c}$ system which leads to enhancement of the C.O.P of the A/C system. In addition, it can be observed that the cycle C.O.P of the $\mathrm{A} / \mathrm{C}$ system with the air guide for sample (2) is larger than that for sample (1) and sample (3) at all inclination angles. The cycle C.O.P of the $\mathrm{A} / \mathrm{C}$ system with the air guide net for sample (2) is about $(12 \%)$ more than that for the other samples (1 and 2$)$ at $\left(15^{\circ}\right)$ inclination angle.

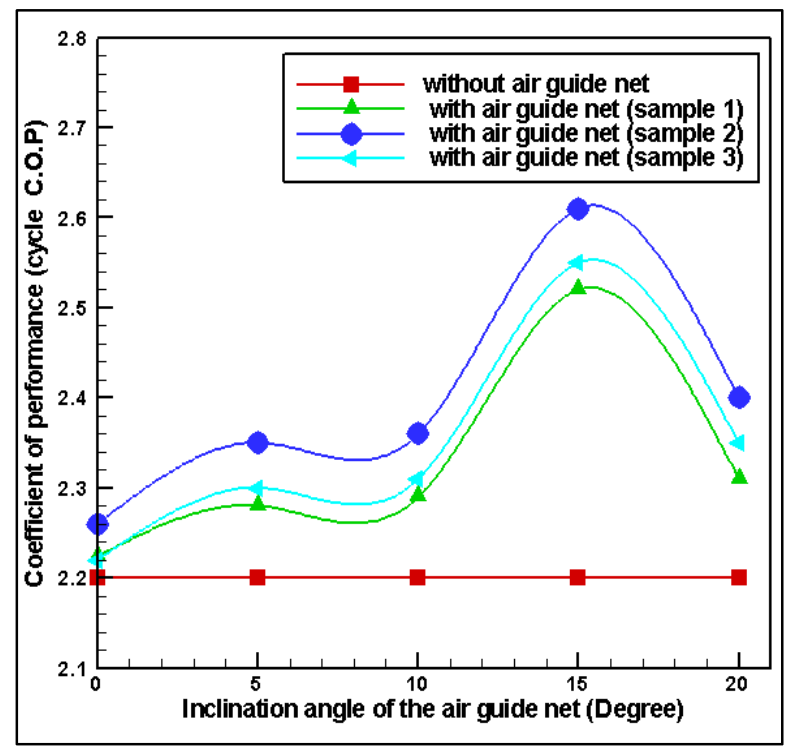

Fig. 8. Variation of cycle C.O.P with inclination angle.

\subsection{The Effect of Air Guide Net on the Input Electric Power}

In this section, the electrical power consumption by the A/C system was evaluated for the two cases, namely without and with air guide net in front of the condenser face. In order to assess the effect of using the air guide net on the input electrical power, and to evaluate the reduction of input electrical power that results from the improvement of the cycle C.O.P of A/C systems, Figure (9) is plotted. This figure shows the representation of the two cases without and with air guide net and for three different air guide net sizes at constant inlet air temperature through the condenser face. This figure depicts the comparison between the $\mathrm{A} / \mathrm{C}$ system without and with air guide net. It is cleary shown that the $\mathrm{A} / \mathrm{C}$ system with an air guide operates with a lower input electrical power comparing with the $\mathrm{A} / \mathrm{C}$ system without air guide net. That means the A/C system without air guide net consumes a higher power than that the $\mathrm{A} / \mathrm{C}$ system with air guide net. It is obvious from this figure that there is a magical increase in the electrical power for the $\mathrm{A} / \mathrm{C}$ system without using air guide net compared to the $\mathrm{A} / \mathrm{C}$ system using air guide net. Also, from Figure (9), it can be seen that the less electrical power consumption is in (sample 3) for the case (C), the $\mathrm{A} / \mathrm{C}$ system with using air guide net (sample 2) and more input electrical power consumption in (sample 1) for the $\mathrm{A} / \mathrm{C}$ system without using the air guide net. The maximum input electrical power is about (1739 Watt) in the case of the $\mathrm{A} / \mathrm{C}$ system without air guide net, and the minimum input electrical power is about (1550 Watt) in the case of the $\mathrm{A} / \mathrm{C}$ system using the guide net (sample 2). This reduction in the input electrical power to the $\mathrm{A} / \mathrm{C}$ system is explained below. As mentioned in previous sections, by using the air guide net, an improvement in the heat dissipation from the condenser is observed during which the discharge temperature of the working fluid (R134a) has been reduced by studying the P-H diagram of working fluid (R134 a). It is known that the lower discharge temperature would reduce the specific volume of the refrigerant working fluid and increase the volumetric efficiency of the compressor, so less power would by consumed at the compressor. And because the compressor consumes the most power of the $\mathrm{A} / \mathrm{C}$ system, the input electrical power would be reduced. A similar trend can be seen for the percentage reduction of input electrical power to the $\mathrm{A} / \mathrm{C}$ system in Figure (10). It can be seen from this figure that for the $\mathrm{A} / \mathrm{C}$ system with the air guide net (sample 1), the input electrical power reduced by about $(2.8 \%)$ in comparison with the $\mathrm{A} / \mathrm{C}$ system without using the guide net, while for the $\mathrm{A} / \mathrm{C}$ system using air guide net (sample 2), the reduction is about (10.1\%), also, for the $\mathrm{A} / \mathrm{C}$ system using air guide net (sample 3), the reduction is about (7.9\%).Thus all results above, show that the $\mathrm{A} / \mathrm{C}$ system with an air guide net 
(sample 2) have a significantly higher percentage reduction in input electrical power than other $\mathrm{A} / \mathrm{C}$ system with air guide net (sample 1 and 3 ).

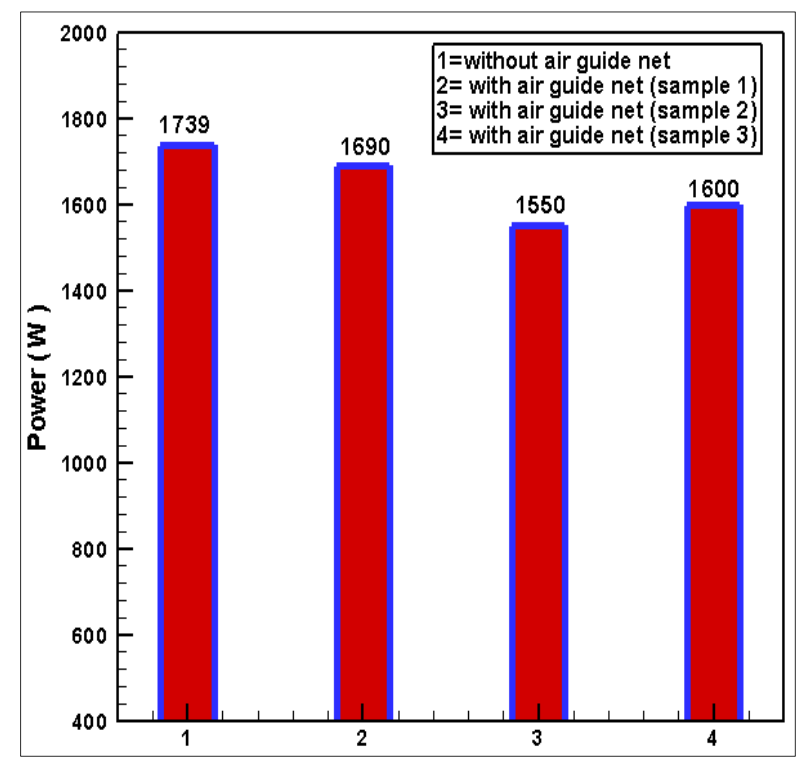

Fig. 9. Graphical representation of the power requirement in the compressor.

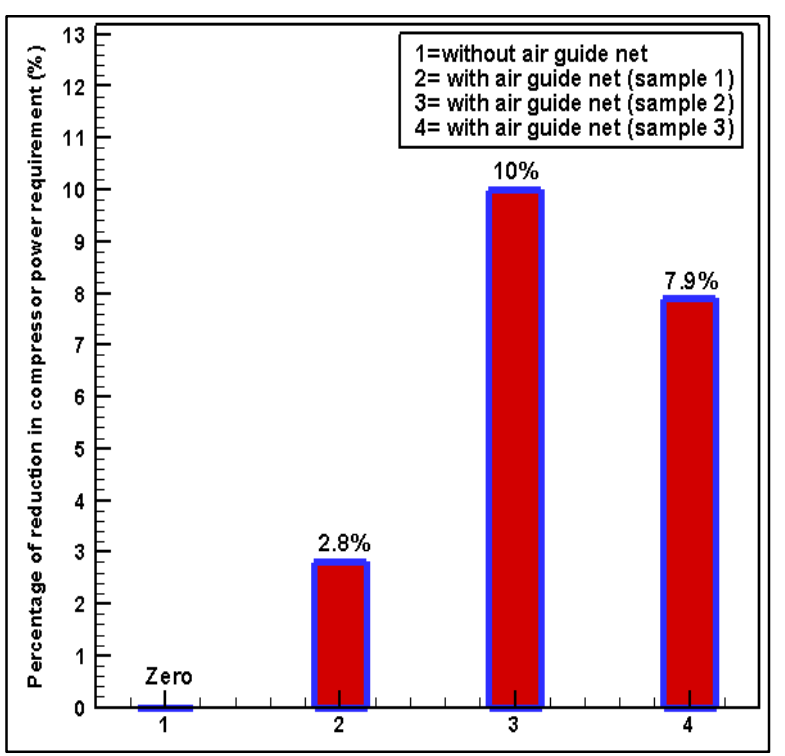

Fig. 10. Graphical representation of percentage of reduction in the compressor power requirement.

\section{Conclusions}

An experimental investigation was conducted on an automobile air-conditioning system without and with an air guide net installed in front of the condenser face to analyze their performance in terms of the coefficient of performance (C.O.P) and power consumption.
From the previous discussion, it can be concluded:

1- The C.O.P of the $\mathrm{A} / \mathrm{C}$ system has been increased by $(13 \%)$ for air guide net (sample $1),(17 \%)$ for air guide net (sample 2) and (14\%) for air guide net (sample 3).

2- The C.O.P is found to be a strong function of air guide net inclination angle especially in the range $(10 o-20 o)$.

3- It is found that in order to obtain a high C.O.P, it is necessary to orient the air guide net at (15o) inclination angle.

4- The A/C system with an air guide net manifested a significant effect on the power consumption. It is obtained that the power consumption in the compressor has been reduced by $(2.8 \%)$ for air guide net (sample 1$)$, $(10 \%)$ for air guide net (sample 2) and (7.9\%) for air guide net (sample 3).

\section{References}

[1] Alison S., Kim T. and Ulrich S., Energy saving measures for automotive air conditioning (AC) system in the tropic, $15^{\text {th }}$ International refrigeration and air conditioning conference at purdu, July 14-17, 2014.

[2] Bhatti M. S., Evaluation of automotive air condition, ASHRAE Journal, 1999, Vol.41, No.9, pp.44-52.

[3] Kiatsiriroat T. and Euakit T., Performance an automotive air condition system with R22, R124, R152a refrigerant, Applied Thermal Engineering, 1997, Vol.17, No.11, PP. 10851097.

[4] Saiz Jabordo, J. M. Gouzalez Mamani, and Ianella W., Modeling and experimental evaluation of an automotive air conditioning system with a variable capacity compressor, International Journal Refrigeration, 2002, Vol. 25, No.8, PP.1157-1172.

[5] Schwarz T. Galluzzi, M. Richardson, D.Radermacher , R. Dickson, and T. Mcgregor I., Model to investigate the performance of accumulators I vapors compression systems, proc. 2002 , 9th International Refrigeration and AirConditioning Conference at Purdue.

[6] G. J.K Awaji, M. Smith-Pollard, and T. Cohon J., Multi-channel R134a two-phase flow measurement technique for automobile air conditioning system, 2003, Proc. 4th ASME/FED and JSME Fluids Engineering Division, Sunmer Meeting. 
[7] Joudi K., A. Mohammed, A.S.K., and Aljanabi M.K., Experimental and computer performance study of an automotive air conditioning system with alternative refrigerants, Energy Conversion and Management Journal, 2003, Vol.44, PP. 2959-2976.

[8] S. Shu, and B. J. Hany, Study of a high efficiency residential split water-cooled air condition, Applied Thermal Engineering Journal, 2005, Vol.25, PP. 1599-1613.

[9] F.W. Yu and K.T. Chan, Advanced control of heat rejection air-flow for improving the coefficient of performance of aircooled chillers, Applied Thermal Engineering Journal, 2006, Vol.26, PP.97-110.

[10] M. L. Jiang, J. Yiwu, Y.X. xn , and R.Z. Wang, Transient characteristics and performance analysis of a vapour compression air conditioning system wiyh condensing heat recovery, Energy and Building Journal 42, ISSUE 11, 2010, PP.2251-2257.

[11] Amaranth, Vineet K., Experimental investigation of the effect of condenser heat exchanger on the room air conditioners performance, International Journal of Engineering Science Invention, ISSUE 7, 2014, Vol. 3 ,PP.5-18.

[12] Aby M.J., Biphin D., Dithin M., and Jacob D., Experimental investigation of different types of condensers on the performance of household refrigerators, International Journal for Innovative Research in Science and Technology, 2017, Vol.3, Issue 11, PP. 23492365.
[13] J.P. Choiu, The effect of air flow non uniformity on the thermal performance of automobile air conditioning condenser, SAE Transaction Journal, 1983, Vol.92, PP. 25872600.

[14] J. W. Coleman and S. mGaarimella, Characterization of two flow patterns in small diameter round and rectangular tubes, International Journal of Heat and Mass Transfer, 2004, Vol.31, PP.1748-1758.

[15] E. Bari, J. Y. Noel,G. Comini , and G. Cortella, Air -coold condensing systems for hom end industrial appliances, Applied Thermal Engineering Journal 2002, Vol.125,PP. 1446-1458.

[16] H. K. Varma, and C. P. Gupta, Heat transfer during forced convection condensation inside horizontal tube, Internatiaonal Jornal Refrigeration, 1995, Vol. 18, PP. 210-214.

[17] M. M. Awad, H. M. Mostafa, G. J. Sutan, A. E. Lbooz, and A. M. K. El-ghomem, Performance enhacement of air-cooled condensers, ACTA Polytechnic Hungarica, 2007, Vol. 4, No.2, PP. 125-142.

[18] X. Z. Song, D. Huong, X. Y. Lin, and Q. Chen, Effect of non-uniform air velocity distribution on evaporator performance and its improvement on a residential air conditioner, Applied Thermal Engineering Journal, 2012, Vol. 40, PP. 284-293.

[19] Zhaoying Z., and Jianguo Y., The effect of face-air velocity distribution on heat transfer performance of air-cooled condensers, International Journal of Heat and Technology, 2015, Vol.33, No.1, PP 55-62. 


\title{
تأثير استعمال شبكة موجة الهواء امام المكثف على اداء منظومة تبريد السيارات
}

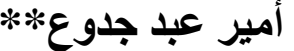 \\ * محمود مصطفى مهدي

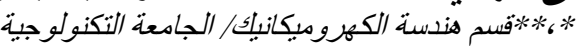

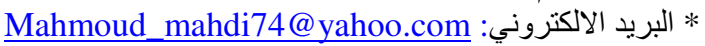

en_ameerabed@yahoo.com البريد الالكتروني:

في هذا البحث تم التركيز على تحسين أداء المكثف لمنظومة تبريد السيارة من خلال تحسين انتقال الحرارة الهوائي وذلك باستعمال شبكة موجة هواء

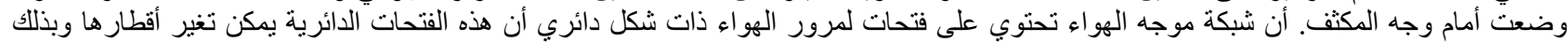

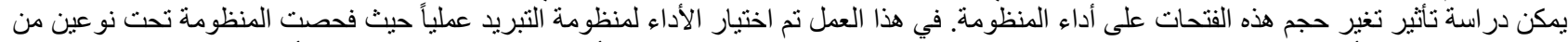

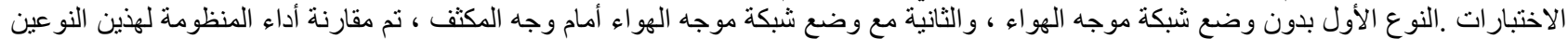

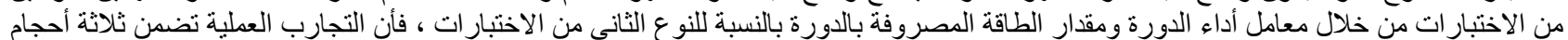

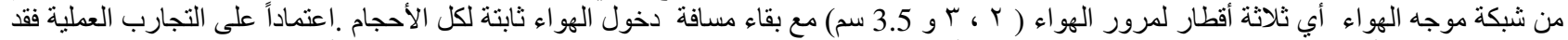

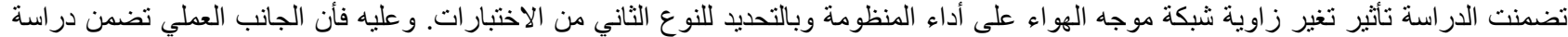

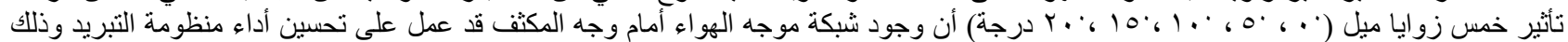

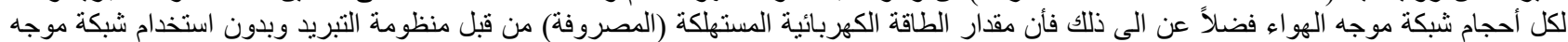

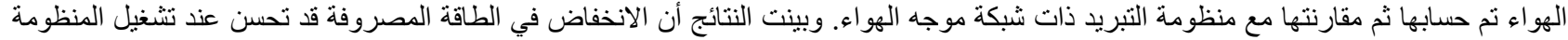

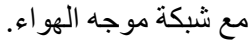

